\title{
Peertechz
}

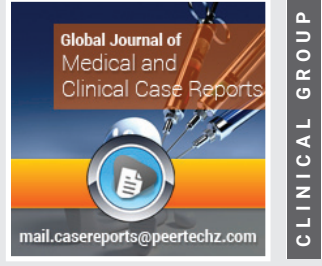

\section{Case Report: An unusual case of} bee envenomation presenting with acute kidney injury,

\section{cavernous venous thrombosis}

\section{and multiple episodes of}

\section{convulsions}

\author{
Walter Otieno ${ }^{1,2 \star}$, Macrine Olwala ${ }^{2}$ and George Michael \\ Odhiambo Owiti ${ }^{1,2}$ \\ ${ }^{1}$ Fellow Nephrology, Maseno University School of Medicine, P.O.Box 333, Maseno, Kenya \\ ${ }^{2}$ Fellow Nephrology, Jaramogi Oginga Odinga Teaching and Referral Hospital, Hospital in Kisumu, \\ Kenya
}

Received: 27 October, 2020

Accepted: 06 November, 2020

Published: 07 November, 2020

*Corresponding author: Walter Otieno, MBChB, M.Med (Paeds), PhD, Maseno University School of Medicine, P.O.Box 333, Maseno, Kenya,

E-mail:Walter.Otieno@usamru-k.org

https://www.peertechz.com

Check for updates

\begin{abstract}
Bee stings are common in the tropics and cause minor problems but may occasionally cause severe anaphylactoid reactions.

Summary of clinical case: We present a case of M.O.0., an 8-year-old boy who was stung three times on the face and developed severe manifestations including acute kidney injury, cavernous sinus thrombosis and multiple convulsions but recovered without sequelae.

Discussion: There is an association between the severity of reaction and the number of bee stings but this case was unique in the sense that we had only 3 stings reported and we developed life threatening clinical manifestations.
\end{abstract}

\section{Introduction}

Envenomation by bees is common world wide and especially in the tropics. The commonest manifestations are local reactions for example vomiting, diarrheoa, generalized oedema and hypotension. On rare occasions, you may get renal, cardiovascular and central nervous complication. We present a case of an 8-year-old boy who developed acute kidney injury, cavernous sinus thrombosis and multiple convulsions but recovered without sequelae.

\section{Case report}

An 8-year-old school boy (M. O. O.) was admitted to our unit with history of bee bite on the face one week prior to admission at a private facility. He was reported to have been stung $\mathrm{x} 3$ by bees. Child was referred and admitted to a private facility on 14th February 2017, where he was found to have generalized oedema, vomiting, cough but no fever.

Initial investigations done revealed normal urinalysis results on $14^{\text {th }}$ February 2017 but a repeat done on $23^{\text {rd }}$ February 2017 showed: proteinuria $(+++)$, red blood cells $(+++)$, pus cells 11-20/hpf, positive leucocyte esterase.

UECs: see the serial levels below but all were deranged and consistent with AKI.

Haemogram showed: Wbc $11.68 \times 10^{9} / \mathrm{L}$, Haemoglobin 


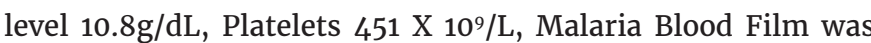
negative for both P. Falciparum and common malaria antigen, LFTs: normal.

Other investigations done were $\mathrm{CPK}, \mathrm{LDH}$ and coagulation screen which were all normal.

Main findings in the initial assessment were ttemperatures of $37^{\circ} \mathrm{C}$ and $\mathrm{SPO}_{2} 92 \%$ off oxygen.

Chest had bilateral rhonchi but no crepitations.

\section{Management}

At admission, the child had not passed urine over the preceding 48 hours.

Later, he developed fever and was started on IV ceftazidime, IV frusemide, IV fluid challenge

Due to the severe bronchospasms, the child was done nebulization with ventolin respirator solution, pulmicort and normal saline with great improvement.

The temperature settled within 24 hours, PR: $67-84$ beats/ min, RR: $19-24 / \mathrm{min}, \mathrm{SPO}_{2} 94 \%-99 \%$. He passed urine after 24 hours but developed recurrent convulsions which did not respond to loading and maintenance doses of IV phenytoin.

MRI scan of the brain revealed bilateral frontoparietal and occipitoparietal laminar infarcts and venous sinus thrombosis.

Child was started on IV heparin and later transitioned to oral warfarin.

Subsequent management: After the initiation of heparin, warfarin, the convulsions abated, child opened up and the general condition improved and he was eventually discharged with no sequelae Tables 1,2.

\section{Discussion}

We describe a complicated case of a young boy who had few bee bites and eventually developed severe manifestations with acute kidney injury, multiple brain infarcts, venous thrombosis and convulsions.

The prevalence of insect sting allergy is estimated to be between $0.5 \%-3 \%$, and people who have previously experienced generalized allergic insect sting reactions are at increased risk for reactions from future stings [1]. The allergic reaction can be triggered by a single sting, and the greater the number of stings, the worse the prognosis because multiple stings lead to inoculation of a higher amount of venom [2].

This was unusual; most cases have been described after multiple envenomation and it is reported that you need about 1500 bites for a $75 \mathrm{~kg}$ person to reach a threshold to give you the manifestations we saw in this child [3]. He had mild venom exposure ( $<1 \mathrm{sting} / \mathrm{kg}$ body weight) which usually has cutaneous manifestations only, but his symptomatology was for high venom exposure ( 4 - 9 stings/kg body weight) [4]. Fewer bee stings are normally not associated with much pathology unless a patient develops anaphylaxis, as is this case.

Bee venom contains peptides, proteins and vasoactive amines for example histamine, acetylcholine, norepinephrine, dopamine and 5-hydroxytryptamine which are thought to be responsible for some of the allergic manifestations [1]. Melittin is the main peptide, and it is the main lethal component of bee venom [2].

The most common manifestations associated with fewer stings include pruritis, hives, oedema, erythema, dizziness, dyspnoea and occasionally anaphylaxis. ${ }^{5}$

Multiple bee stings may be associated with various organ dysfunctions, namely $[1,4]$ :

Cardiovascular (coronary vasospasm, myocardial infarction secondary to allergic reactions [Kounis syndrome], shock, cardiac arrhythmia and cardiac arrest.

Respiratory (bronchospasm, pulmonary haemorrhage, acute respiratory distress syndrome and respiratory failure.

Haematological (Immune Thrombocytopaenic Purpura (ITP), immune mediated haemolytic anaemia, Disseminated Intravascular Coagulation (DIC) and Henoch-Schonlein purpura

Renal (rhabdomyolysis, nephrotic syndrome and Acute Kidney Injury (AKI)

Hepatobiliary (acute autoimmune hepatitis)

Pancreas (haemorrhagic pancreatitis)

Neurological manifestations (encephalitis, acute disseminated encephalomyelitis [ADEM], peripheral neuritis and cerebral infarction.

Table 1: Labaratory data on serial U/E/Cr (2017).

\begin{tabular}{|c|c|c|c|c|c|c|c|c|c|c|c|c|c|c|c|c|}
\hline Date & $14 / 2$ & $15 / 2$ & $16 / 2$ & $17 / 2$ & $18 / 2$ & $19 / 2$ & $20 / 2$ & $21 / 2$ & $22 / 2$ & $23 / 2$ & $25 / 2$ & $26 / 2$ & $1 / 3$ & $2 / 3$ & $3 / 3$ & $4 / 3$ \\
\hline $\mathrm{Na}+$ & 132 & 132 & 123 & 126 & 123 & 130 & 128 & 128 & 129 & 124 & 121 & 135 & 137 & 139 & 139 & 136 \\
\hline K+ & 5.2 & 5.2 & 4.8 & 5.3 & 5.1 & 5.4 & 5.5 & 5.2 & 4.8 & 4.4 & 3.7 & 4.6 & 3.5 & 3.3 & 3.9 & 4.1 \\
\hline Cl- & 101 & 98 & 94 & 91 & 91 & 90 & 96 & 92 & 95 & 93 & 95 & 100 & 104 & 107 & 107 & 107 \\
\hline S-CO2 & 18 & 17 & 16 & 18 & 16 & 19 & 19 & 19 & 21 & 15 & 23 & 22 & 26 & 28 & 25 & 20 \\
\hline S-anion gap & 13 & 15 & 13 & 17 & 16 & 21 & 13 & 15 & 13 & 15 & 3 & 13 & 7 & 4 & 7 & 9 \\
\hline S-Urea & 39.9 & 41.3 & 38.9 & 40.0 & 41.7 & 41.0 & 39.6 & 40.3 & 37.5 & 34.5 & 25.3 & 24.1 & 12.7 & 11.8 & 9.9 & 9.3 \\
\hline S-Creatinine & 436 & 485 & 427 & 338 & 313 & 296 & 292 & 269 & 273 & 244 & 176 & 184 & 148 & 155 & 161 & 172 \\
\hline & & & & & & & & & & & & & & & & 104 \\
\hline
\end{tabular}

Citation: Otieno W, Olwala M, Odhiambo Owiti GM (2020) Case Report: An unusual case of bee envenomation presenting with acute kidney injury, cavernous venous thrombosis and multiple episodes of convulsions. Glob J Medical Clin Case Rep 7(2): 103-106. D0I: https://dx.doi.org/10.17352/2455-5282.000109 
Table 2: Serial PT, PTI and INR.

\begin{tabular}{|c|c|c|c|c|}
\hline Date & $\mathbf{1 6 / 2 / 1 7}$ & $\mathbf{2 5 / 2 / 1 7}$ & $\mathbf{2 / 3 / 1 7}$ & $\mathbf{3 / 3 / 1 7}$ \\
\hline Prothrombin Time & 13.1 & 12.6 & 12.6 & 14.1 \\
\hline Control Time & 11.8 & 11.8 & 11.8 & 11.8 \\
\hline Prothrombin Index (\%) & 90 & 93 & 93 & 83 \\
\hline INR & 1.11 & 1.07 & 1.07 & 1.19 \\
\hline
\end{tabular}

Musculoskeletal (myasthenia gravis and Guillain-Barre syndrome (GBS)

Others manifestations include serum sickness and Reyelike syndrome.

\section{Acute kidney injury}

AKI caused by bee stings are often accompanied with multiple organ dysfunction syndrome (MODS), with the mortality rate ranging from $9.3 \%$ to $60 \%$. It is usually observed 48-72 hours after the accident, just like it happened in this case [6].

The mechanism through which renal damage occurs following bee venom inoculation is not fully understood $[2,6]$. Multiple factors, such as intravascular hemolysis, rhabdomyolysis, hypotension, low cardiac output, and direct toxicity of the venom components to the renal tubules by possible melittin-induced apoptosis, may contribute to the pathophysiology [7].

Intravascular haemolysis and rhabdomyolysis: peptides such as melittin, apalim and phospholipase A can provoke these processes, and they are demonstrated by elevated serum levels of indirect bilirubin and creatine kinase.

Rhabdomyolysis causes renal vasoconstriction, formation of intratubular deposits of myoglobin, direct cytotoxicity of myoglobin to the renal tubule cell and DIC, which leads to the release of thromboplastin, thus formation of microthrombi in the glomeruli. All these consequently cause reduced Glomerular Filtration Rate (GFR).

Hypotension: The same peptides mentioned above, amongst others, can induce the release of several other mediators, such as histamine, serotonin, bradykinin and prostaglandins, which are vasoactive and may lead to a reduction in systemic blood pressure.

In addition, melittin has depressive and cardiotoxic effects; in large quantities, it causes cardiac spasm and cardiovascular collapse. Apamin acts as a neurotoxin with motor action, causing systemic vasodilation. Both these substances generate severe hypotension and increased heart rate.

Renal hypoperfusion activates the renin-angiotensinaldosterone system, leading to vasoconstriction of both afferent and efferent arterioles, worsening the GFR; thus, ischaemia and development of Acute Tubular Necrosis (ATN).

\section{Brain infarcts}

An MRI scan of the brain, done when the child began convulsing, revealed bilateral frontoparietal and occipitoparietal laminar infarcts. Neurological manifestations of bee stings are rare [8]. The exact pathophysiology explaining strokes due to honey bee bite is still unknown. Possible causes include hypotension inducing cerebral ischaemia, exogenous adrenaline, and thromboxane and leukotrienes within the venom, causing vasoconstriction, platelet aggregation secondary to various compounds released, cerebral embolism, hypertensive haemorrhage and DIC $[8,9]$.

\section{Cavernous Sinus Thrombosis (CST)}

The MRI scan also showed venous sinus thrombosis. Unfortunately, there is paucity of data in the incidence and possible pathophysiology that may lead to this following bee venom inoculation. One previous case of a 58-year-old man who was bitten by a bee on his left upper lip, and subsequently developed CST 48 hours later, is found in literature [10]. Possible reasons for formation of the CST included: thrombophlebitis of the facial vein induced by thrombogenic substances of the venom, direct inoculation of bacteria from the insect's body or the surface of the victim's skin, into the epidermis, scratching due to itching thus further epidermal injury and intra-dermal implantation of pathogenic bacteria, impaired lymphatic drainage due to local oedema, thus reduced clearance of the infection by the immune system.

\section{Immediate management}

This should consist of epinephrine $0.01 \mathrm{mg} / \mathrm{kg}$ of $1: 1000$. Repeat every 5-15 minutes, Antihistamine, $\mathrm{H}_{2}$ receptor antagonist, Inhaled bronchodilators, Glucocorticoids, and in severe cases, intubation.

\section{Consent to publish}

Verbal informed consent was obtained from the parent of the patient for publication of this case.

\section{References}

1. Moffitt JE (2003) Allergic reactions to insect stings and bites. South Med J 96: 1073-1080. Link: https://bit.ly/32IH7yK

2. da Silva GB, Vasconcelos AG, Rocha AMT, de Vasconcelos VR, de Barros Neto $\mathrm{J}$, et al. (2017) Acute kidney injury complicating bee stings - A review. Revista do Instituto de Medicina Tropical de Sao Paulo 59. Link: https://bit.ly/36bj0Uu

3. Goddard J (2010) Physician's Guide to Arthropods of Medical Importance. Edition 4, Illustrated, Revised, CRC Press.

4. McKenna WR, Brown TC (2017) Unique Aspects of Bee Allergy and Reactions In Stinging Insect Allergy (Springer International Publishing) 155-187. Link: https://bit.ly/2GFLdKm

5. José Pérez-Pimiento A, Alonso-González L, Prieto-Lastra L, Isabel RodríguezCabreros M, Iglesias-Cadarso A, et al. (2005) Anaphylaxis to hymenoptera sting: study of 113 patients. Medicina Clínica 125: 417-420. Link: https://bit.ly/3pdna75

6. Bridi RA, Balbi AL, Neves PM, Ponce D (2014) Acute kidney injury after massive attack of Africanised bees. BMJ Case Reports 2014: bcr2013201381. Link: https://bit.ly/357nzjf

7. Shu Y, Yang Y, Zhao Y, Ma L, Fu P, et al. (2019) Melittin inducing the apoptosis of renal tubule epithelial cells through upregulation of Bax/Bcl-2 expression 
and activation of TNF- Signaling pathway. BioMed Research International 2019. Link: https://bit.ly/353LVdy

8. Temizoz O, Celik Y, Asil T, Balci K, Unlu E, et al. (2009) Stroke due to bee sting. Neurologist 15: 42-43. Link: https://bit.ly/2ldkbKN

9. Jain J, Banait S, Srivastava A, Lodhe R (2012) Stroke intracerebral multiple infarcts: Rare neurological presentation of honey bee bite. Annals of Indian Academy of Neurology 15: 163-163. Link: https://bit.ly/352YgyJ

10. Senthilkumaran S, Sweni S, Balamurugan N, Thirumalaikolundusubramanian $P$ (2011) Cavernous sinus thrombosis following bee sting. International Journal of Critical Illness and Injury Science 1: 167. Link: https://bit.ly/3k9TBPM
Discover a bigger Impact and Visibility of your article publication with Peertechz Publications

\section{Highlights}

* Signatory publisher of ORCID

* Signatory Publisher of DORA (San Francisco Declaration on Research Assessment)

* Articles archived in worlds' renowned service providers such as Portico, CNKI, AGRIS, TDNet, Base (Bielefeld University Library), CrossRef, Scilit, J-Gate etc.

* Journals indexed in ICMJE, SHERPA/ROMEO, Google Scholar etc.

* OAI-PMH (Open Archives Initiative Protocol for Metadata Harvesting)

* Dedicated Editorial Board for every journa

* Accurate and rapid peer-review process

- Increased citations of published articles through promotions

* Reduced timeline for article publication

Submit your articles and experience a new surge in publication services (https://www.peertechz.com/submission).

Peertechz journals wishes everlasting success in your every endeavours.

Copyright: @ 2020 Otieno W, et al. This is an open-access article distributed under the terms of the Creative Commons Attribution License, which permits unrestricted use distribution, and reproduction in any medium, provided the original author and source are credited.

Citation: Otieno W, Olwala M, Odhiambo Owiti GM (2020) Case Report: An unusual case of bee envenomation presenting with acute kidney injury, cavernous venous thrombosis and multiple episodes of convulsions. Glob J Medical Clin Case Rep 7(2): 103-106. DOI: https://dx.doi.org/10.17352/2455-5282.000109 